\title{
Technology of Porous Tantalum Production
}

\author{
Yu. Zh. Tuleushev, V. N. Volodin, E. A. Zhakanbaev, V. N. Lisitsin, A. A. Migunova, \\ A. S. Suleymenova \\ Institute of Nuclear Physics, Almaty, Republic of Kazakhstan \\ Email: yuriy.tuleushev@mail.ru
}

Received 8 April 2016; accepted 6 June 2016; published 9 June 2016

Copyright (C) 2016 by authors and Scientific Research Publishing Inc.

This work is licensed under the Creative Commons Attribution International License (CC BY).

http://creativecommons.org/licenses/by/4.0/

(c) (i) Open Access

\begin{abstract}
Ion-plasma sputtering and codeposition of ultrafine Ta and Cd particles on a moving substrate were used to prepare the solid solutions, in particular, the alloys with up to 66.2 at.\% Cd in the form of coatings. In vacuum heat treatment cadmium evaporates at $700^{\circ} \mathrm{C}$ from cadmium based solid solutions resulting in formation of a porous tantalum with a highly developed surface. The prepared tantalum-based materials assume the technological application of the investigation results.
\end{abstract}

Keywords

Tantalum, Cadmium, Porous Structures, Specific Surface

\section{Introduction}

The methods for preparing of porous metals, known to date, are multi-staged and complicated [1] [2]. The authors find it tempting to find an alternative method of preparing a porous refractory metal in the coating using the technique of magnetron sputtering with two magnetrons [3]-[6]. For this purpose, the most promising seems the preparation of a mixture of refractory metal (tantalum) with metal characterized by high vapor pressure at a relatively low temperature, cadmium.

It is known that tantalum and cadmium can't form the intermetallic compounds and alloys [7]. Tantalum has two modifications: $\alpha$-Ta with a body-centered cubic lattice $a=0.3305 \mathrm{~nm}$ and $\beta$-Ta with a tetragonal lattice $(a=$ 1.0194 and $c=0.5313 \mathrm{~nm})$. It is known [8], that $\beta$-Ta is produced in the form of fine-grained powder using electrolysis of salt melts. The papers [9] [10] report about $\beta$-Ta thin films preparation by dc-magnetron sputtering. Subsequent heating to $1000^{\circ} \mathrm{C}$ is accompanied by an irreversible $\beta$-Ta to $\alpha$-Ta transition that confirms the meta-stability of the $\beta$-phase. The mechanism of $\beta$-Ta formation and the features of the crystal lattice belonging to this phase are described in [11].

Our preliminary studies related to the preparation of tantalum coatings by ion-plasma sputtering showed that the change of tantalum modification may be due to the concentration of dissolved metal [3], as well as the size

How to cite this paper: Tuleushev, Yu.Zh., Volodin, V.N., Zhakanbaev, E.A., Lisitsin, V.N., Migunova, A.A. and Suleymenova, A.S. (2016) Technology of Porous Tantalum Production. World Journal of Nano Science and Engineering, 6, 51-57. 
of ultra dispersed particles.

The potential application of film tantalum in the form of porous coating, prepared as an alloy and followed by removal of the second metal, has determined the interest towards possible preparation of tantalum-cadmium solid solutions and their structure. The peculiarity of this system is the absence of cadmium solubility in tantalum under normal conditions and the high pressure of cadmium vapor at relatively low temperatures (boiling temperature at atmospheric pressure is $766.3^{\circ} \mathrm{C}$ ), which determines the possibility to transfer cadmium from solutions into the vapor at relatively low temperatures [9] with the pores remaining in the tantalum matrix.

In this regard, the aim of the completed investigation was to study the morphology, the phase composition, depending on metals concentration, and the thermal resistance of the tantalum-cadmium coatings.

\section{Experimental}

We studied the tantalum-cadmium films prepared by codeposition of ultrafine particles of the metals, which were obtained by ion-plasma sputtering on cols substrates made from monocrystalline silicon.

We used tantalum with 99.96 mas.\% of main element and cadmium (99.99 mas.\%) in the form of targets 40 $\mathrm{mm}$ in diameter and $4 \mathrm{~mm}$ thick for application of film coatings. Argon was used as the plasma-forming gas, purified with a sputtered titanium getter.

Samples of coatings were prepared by the procedure implying ion-plasma sputtering of tantalum and cadmium and cooperative deposition of ultra dispersed particles on the substrates moving with respect to plasma flows in the form of short period (with a low number of crystal lattice periods) sublayers that form films of 0.7 $3.1 \mu \mathrm{m}$ total thickness. The velocity of substrate movement was $5 \times 10^{-2} \mathrm{~m} \cdot \mathrm{s}^{-1}$ with respect to metal containing plasma flow. The sputtering was performed with the simultaneous use of two magnetrons located opposite one another; the spacing between magnetrons was separated by a unit for the substrates movement.

The composition of coatings was controlled by varying the powers supplied to magnetrons sputtered tantalum and cadmium targets. The concentration of deposited metals was verified by the weighing method, i.e. the amounts of each metal sputtered and deposited during the formation of coating were determined [3]-[6]. The film thickness was determined by Rutherford proton back-scattering spectrometry using UKP-2-1 tandem accelerator in the Institute of Nuclear Physics (Republic of Kazakhstan) and was calculated using the amounts of deposited metals. Electron-microscopic studies were performed using a JEM-8230 (JEOL) electron-microprobe analyzer. The X-ray diffraction studies were performed using a D8 Advance (Bruker) diffractometer with copper irradiation $\lambda_{\mathrm{k} \alpha}=0.154051 \mathrm{~nm}$ and graphite monochromator in the $\Theta-2 \Theta$ mode. The lattice parameters were determined by averaging of the magnitudes obtained using all diffraction reflections of the identified phase.

High-temperature annealing was performed in a vacuum high-temperature furnace that was designed based on URVT-2500 unit.

\section{Results and Discussion}

The samples of tantalum-cadmium films containing 0.7 - 87.6 at.\% $\mathrm{Cd}$ were prepared and the phase composition of the coatings was determined. To study the thermal stability of the prepared tantalum-cadmium coating, the isochronous $\left(1 \mathrm{~h}\right.$ ) vacuum annealing at $300^{\circ} \mathrm{C}-700^{\circ} \mathrm{C}$ (with $100^{\circ} \mathrm{C}$ step) were performed.

The phases identified in the film coating and the calculated parameters of the lattice in the initial state are shown in Table 1.

The phase analysis of the samples showed that, as the cadmium content in the Ta-Cd coatings changes, the following four concentration ranges can be distinguished: 0 - 44.0 at.\% $\mathrm{Cd}$ range corresponding to existence of $\beta$-Ta phase; 48.8 - 56.6 at. $\% \mathrm{Cd}$ range corresponding to existence of $\beta$-Ta and $\alpha$-Ta phases; $59.6-66.2$ at.\% Cd range, corresponding to $\alpha$-Ta only; $74.4-100$ at.\% Cd corresponding to the presence of cadmium and amorphous tantalum. At cadmium content of 48.8 at.\% the $\beta$-Ta phase is highly grain-orientated (001), therefore it is not possible to determine the lattice parameters $a$ and $b$. The parameters of $\beta$-Ta lattice slightly linearly decrease with cadmium concentration increase in the coating in accordance with the dependencies: $a[\mathrm{~nm}]=1.0186-3 \times$ $10^{-6} x_{\mathrm{Cd}} ; c[\mathrm{~nm}]=0.5319-3 \times 10^{-5} x_{\mathrm{Cd}}$, hereinafter $x_{\mathrm{Cd}}$ is the cadmium concentration, at. $\%$.

It is known from [9] that the atomic radius of $\mathrm{Ta}$ and $\mathrm{Cd}$ is $0.1626 \mathrm{~nm}$ and $0.1727 \mathrm{~nm}$, respectively. Considering these values, formation of a substitute solid shall be accompanied by the increase in the $\beta$-Ta lattice parameter during placing of the impurity atoms in the basal planes of the unit cell. The opposite variations in the cell parameters indicate the presence of cadmium atoms in the internal channels of $\beta$-tantalum unit cell [10], as 
Table 1. Identified phases and parameters of their lattices in the tantalum-cadmium films.

\begin{tabular}{|c|c|c|c|c|c|}
\hline \multirow{2}{*}{$\begin{array}{l}\text { Cd concentration in } \\
\text { the coating, at. } \%\end{array}$} & \multicolumn{2}{|c|}{$\beta$-Ta, tetragonal lattice, $\mathrm{nm}$} & \multirow{2}{*}{$\frac{\alpha \text {-Ta, cubic lattice, } \mathrm{nm}}{a}$} & \multicolumn{2}{|c|}{$\mathrm{Cd}$, hexagonal lattice, $\mathrm{nm}$} \\
\hline & $a$ & $c$ & & $a$ & $c$ \\
\hline 6.7 & $1.0095 \pm 0.0018$ & $0.5333 \pm 0.0018$ & - & - & - \\
\hline 9.9 & $1.0213 \pm 0.0010$ & $0.5307 \pm 0.0010$ & - & - & - \\
\hline 13.9 & $1.0214 \pm 0.0011$ & $0.5310 \pm 0.0011$ & - & - & - \\
\hline 17.0 & $1.0207 \pm 0.0007$ & $0.5306 \pm 0.0007$ & - & - & - \\
\hline 17.3 & $1.0204 \pm 0.0005$ & $0.5307 \pm 0.0005$ & - & - & - \\
\hline 22.9 & $1.0224 \pm 0.0011$ & $0.5301 \pm 0.0011$ & - & - & - \\
\hline 25.3 & $1.0199 \pm 0.0012$ & $0.5335 \pm 0.0012$ & - & - & - \\
\hline 30.4 & $1.0145 \pm 0.0007$ & $0.5319 \pm 0.0007$ & - & - & - \\
\hline 38.0 & $1.0215 \pm 0.0009$ & $0.5300 \pm 0.0009$ & - & - & - \\
\hline 44.0 & $1.0153 \pm 0.0002$ & $0.5343 \pm 0.0002$ & - & - & - \\
\hline 48.8 & - & 0.5334 & $0.3343 \pm 0.0001$ & - & - \\
\hline 56.6 & 1.0740 & 0.5338 & $0.3340 \pm 0.0038$ & - & - \\
\hline 61.3 & - & - & $0.3361 \pm 0.0002$ & - & - \\
\hline 66.2 & - & - & $0.3351 \pm 0.0001$ & - & - \\
\hline 74.4 & - & - & - & 0.29769 & 0.56154 \\
\hline 75.4 & - & - & - & 0.29772 & 0.56136 \\
\hline 87.6 & - & - & - & 0.29785 & 0.56114 \\
\hline
\end{tabular}

for Ta-Cu system [2].

Formation of cadmium solid solution in $\alpha$-Ta is accompanied by a slight increase in the size of the body-centered cubic lattice within the concentration range of the phase existence according to the dependence: $a$ $[\mathrm{nm}]=0.3305+8 \times 10^{-5} x_{\mathrm{Cd}}$, enabling us to suggest the formation of a substitution solid solution.

The opposite variations of the lattice parameters $a[\mathrm{~nm}]=0.2968+1 \times 10^{-5} x_{\mathrm{Cd}}$ and $c[\mathrm{~nm}]=0.5633-3 \times$ $10^{-5} x_{\mathrm{Cd}}$ allow us to assume the interstitial arrangement of tantalum atoms in the basal plane of cadmium hexagonal crystal lattice of coatings corresponding to the mentioned concentration range of coatings composition.

SEM studies of the morphology of the coating in the initial state and after annealing were performed for the compositions with $30.4,56.6$ and 74.4 at.\% Cd.

The electron-microscopic studies showed that, in the initial state with 30.4 at.\% Cd (see Figure 1) the coating is characterized by a flat surface with fine projected crystallites of $300-400 \mathrm{~nm}$ maximal size.

After annealing at $700^{\circ} \mathrm{C}$ the sizes of projected formations decreases; between some crystallites small pores less than $100 \mathrm{~nm}$ in lateral size are present, which result from the evaporation of cadmium from the solid solution.

Figure 2 provides the diffraction patterns of the coating with 30.4 at. $\% \mathrm{Cd}$ in the initial state (spectrum a) and after annealing at $300^{\circ} \mathrm{C}$ (spectrum b), $600^{\circ} \mathrm{C}$ (spectrum c) and $700^{\circ} \mathrm{C}$ (spectrum d).

In the initial state and after annealing at $400^{\circ} \mathrm{C}, 500^{\circ} \mathrm{C}$ and $600^{\circ} \mathrm{C}$ the coating is represented by $\beta$-tantalum phase (Figure 2, spectra a-c). At the increase of annealing temperature up to $700^{\circ} \mathrm{C}$ the coating is represented by a mixture of $\alpha$ - and $\beta$-Ta phases (Figure 2, spectrum d). The parameter of the body-centered cubic lattice $\alpha$-Ta is $a=0.3311 \pm 0.0001 \mathrm{~nm}$.

With increase of vacuum heat treatment temperature from $300^{\circ} \mathrm{C}$ to $700^{\circ} \mathrm{C}$, accompanied with cadmium evaporation from its solid solution with tantalum, the parameters of the $\beta$-Ta lattice increases relatively to those determined in the initial sample. If the parameter $c$ of the tetragonal lattice approaches the tabular value, the parameter $a$ significantly exceeds it. In our opinion, this can be explained by thermally initiated process of cadmium atoms replacement from the internal channels of the unit cell of $\beta$-tantalum into the nodes, located in the basal plane $a b$. It follows that in the internal channels the impurity atoms have a lower energy than those in the nodes, 


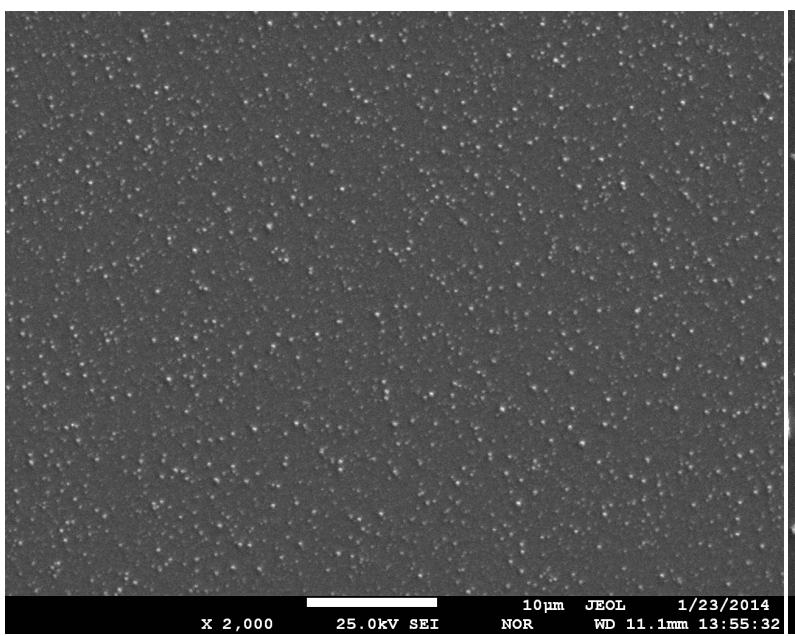

(a)

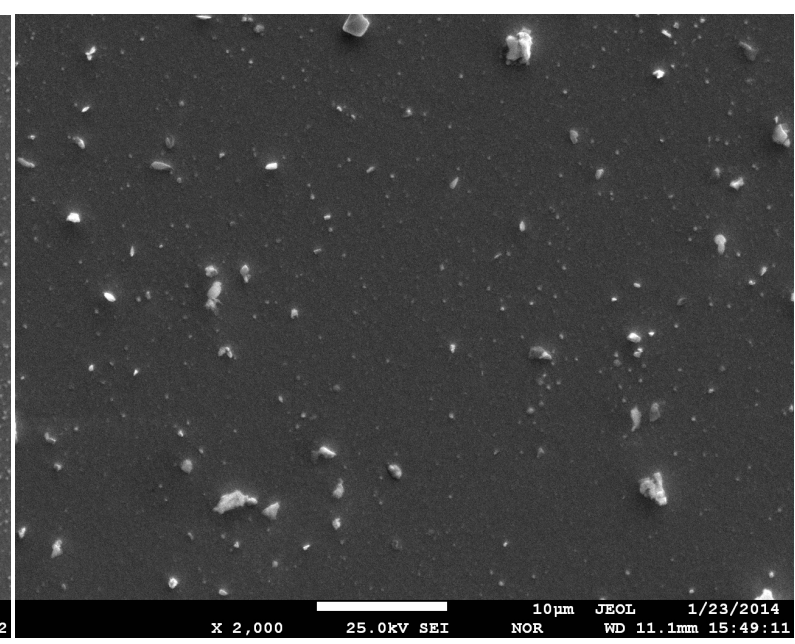

(b)

Figure 1. SEM micrographs of the coating with 30.4 at.\% $\mathrm{Cd}$ before (a) and after annealing at $700^{\circ} \mathrm{C}$ (b).

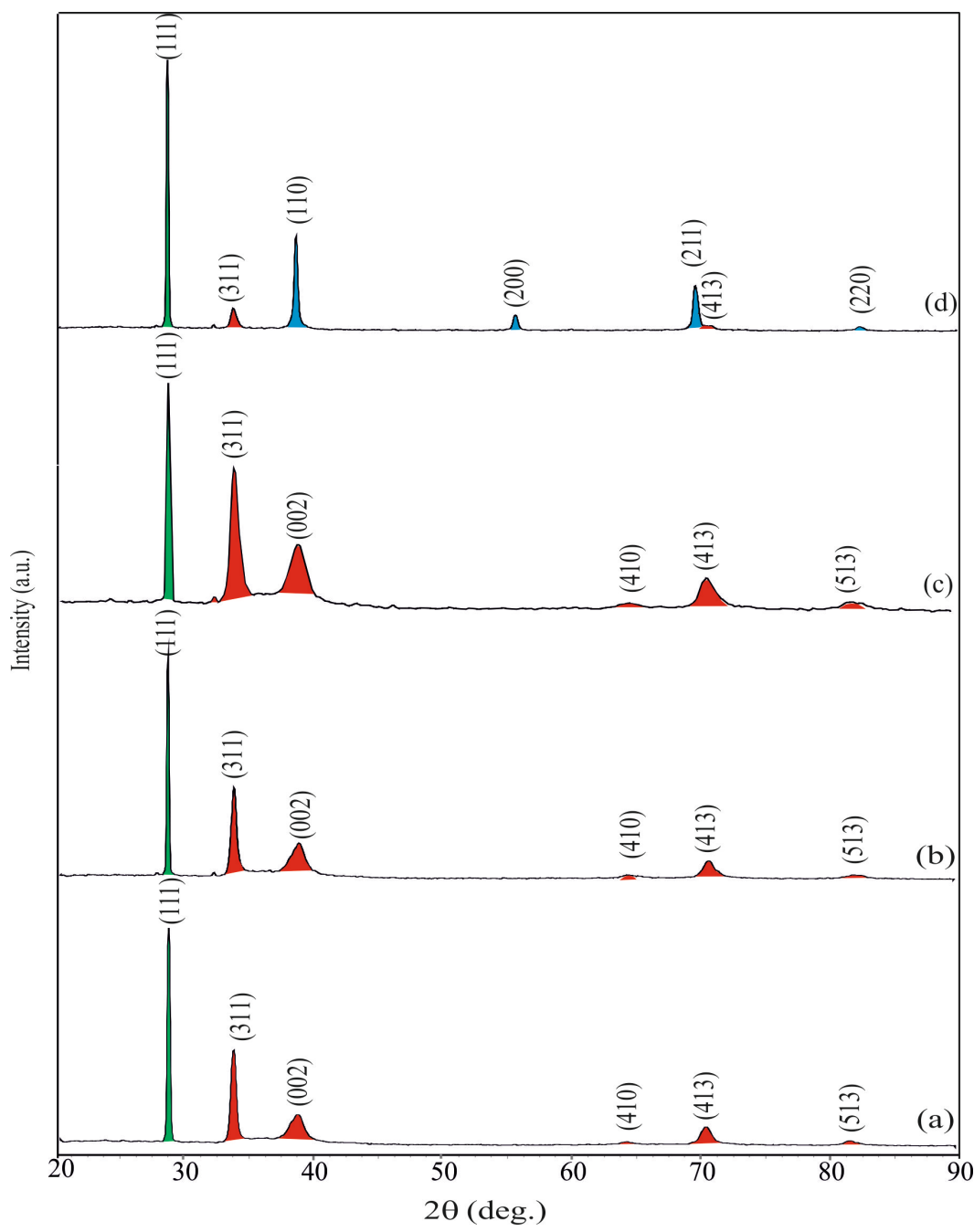

Figure 2. X-ray diffraction patterns of the coating with 30.4 at. $\% \mathrm{Cd}: 1$ - in the initial state, 2 -after annealing at $300^{\circ} \mathrm{C}$; 3 - the same at $600^{\circ} \mathrm{C} ; 4$ - the same at $700^{\circ} \mathrm{C} ; \square-\beta-\mathrm{Ta} ; \square \_\alpha-\mathrm{Ta} ; \square-\mathrm{Si}$ (substrate). 
located in the basal plane $a b$.

The annealing of the sample with 56.6 at.\% Cd, which in the initial state, consists of the fine-grained mixture of $\alpha$ - and $\beta$-Ta phases, showed their stability up to the temperature $600^{\circ} \mathrm{C}$, while at $700^{\circ} \mathrm{C}$ the major portion of $\beta$-Ta modification transforms into $\alpha$-tantalum. The electron-microscopic study of this sample (Figure 3) enabled us to find the existence of a great amount of through pores after annealing at $700^{\circ} \mathrm{C}$ compared with the sample with 30.4 at. $\% \mathrm{Cd}$.

The phase composition of coating with $74.4,75.4$ and 87.6 at.\% $\mathrm{Cd}$ is represented by cadmium with a hexagonal lattice and amorphous tantalum (Figure 4), the amount of which (according to halo) decreases with increasing of cadmium content in the coating. In this case, the lattice parameters of cadmium slightly vary irregularly from $a=0.29769 \mathrm{~nm}$ and $c=0.56154 \mathrm{~nm}$ at 74.4 at.\% Cd to $a=0.29785 \mathrm{~nm}$ and $c=0.56114 \mathrm{~nm}$ at 87.6 at.\% Cd, respectively.

This fact allows us to state that the coating contains the solid solution of tantalum in cadmium with the hexagonal lattice. Since a portion of tantalum precipitates in the form of individual amorphous phase, it was impossible to calculate the amount of tantalum dissolved in cadmium.

SEM studies of the morphology of the coating with 74.4 at.\% Cd showed that the coating in the initial state is represented by the conglomerate of closely adjoining crystallites of the round shape (Figure 5(a)). After vacuum annealing at $700^{\circ} \mathrm{C}$ the surface of the coating is characterized by the presence of elements with similar shape to that of crystallites in the initial sample (Figure 5(b)), free of cadmium according to the X-ray diffraction analysis. The microprobe analysis of the same sample after annealing showed cadmium concentration in the coating at the detection limit. That is, the thermal stability of the coatings with high cadmium content is very low at low pressures the temperature increase is accompanied by almost complete evaporation of the latter.

This behavior of the tantalum-cadmium film coating makes it possible to prepare a porous tantalum with the developed surface by forming the film with Ta concentration less than 30 at.\% (Cd is remaining) and subsequent distillation of volatile metal.

The assessment of the specific surface area of the film tantalum and porous tantalum coating, performed by BET method, revealed the increase in the specific surface area by at least $277.5 \mathrm{~m}^{2} / \mathrm{g}$ Ta only because of pore 10 $\mathrm{nm}$ in diameter.

\section{Conclusions}

The performed studies have shown that magnetron preparation of coatings from a mixture of tantalum and cadmium, and subsequent removal of cadmium from the coating by vacuum annealing can be used to prepare the coatings from a porous tantalum with a very developed surface area. It is shown that porous tantalum has a body-centered cubic lattice, i.e., it is $\alpha$-tantalum and formed by recrystallization of the amorphous tantalum.

The obtained results of the study may be applied for other binary systems consisting of metals and materials

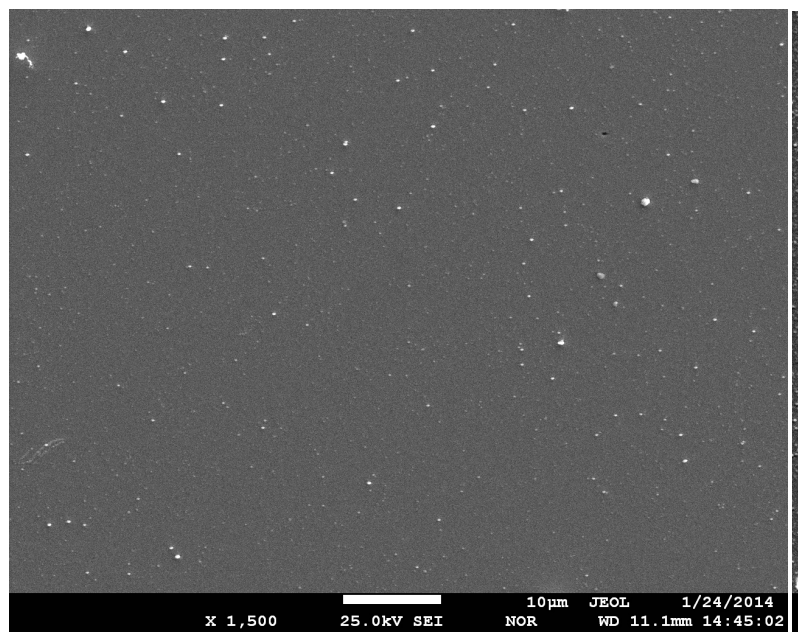

(a)

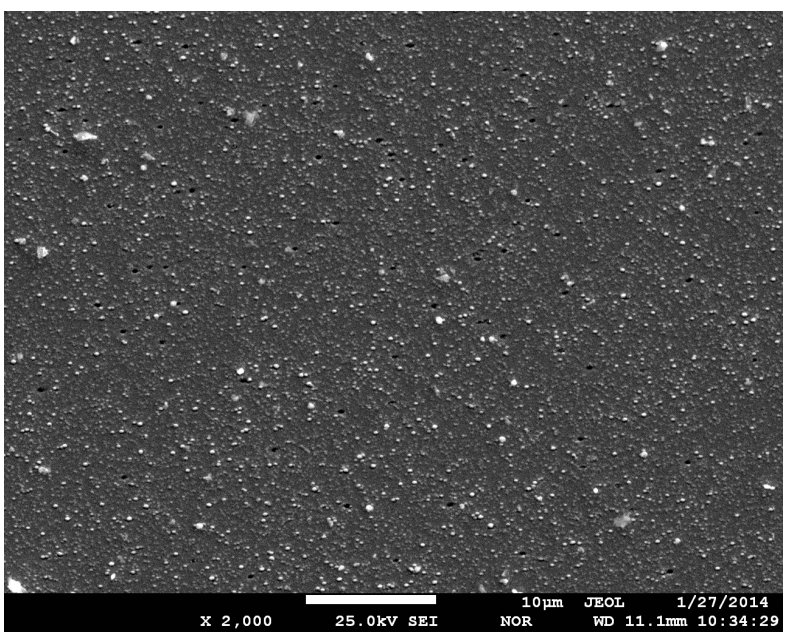

(b)

Figure 3. SEM micrographs of the coating with 59.6 at.\% $\mathrm{Cd}$ before (a) and after annealing at $700^{\circ} \mathrm{C}$ (b). 


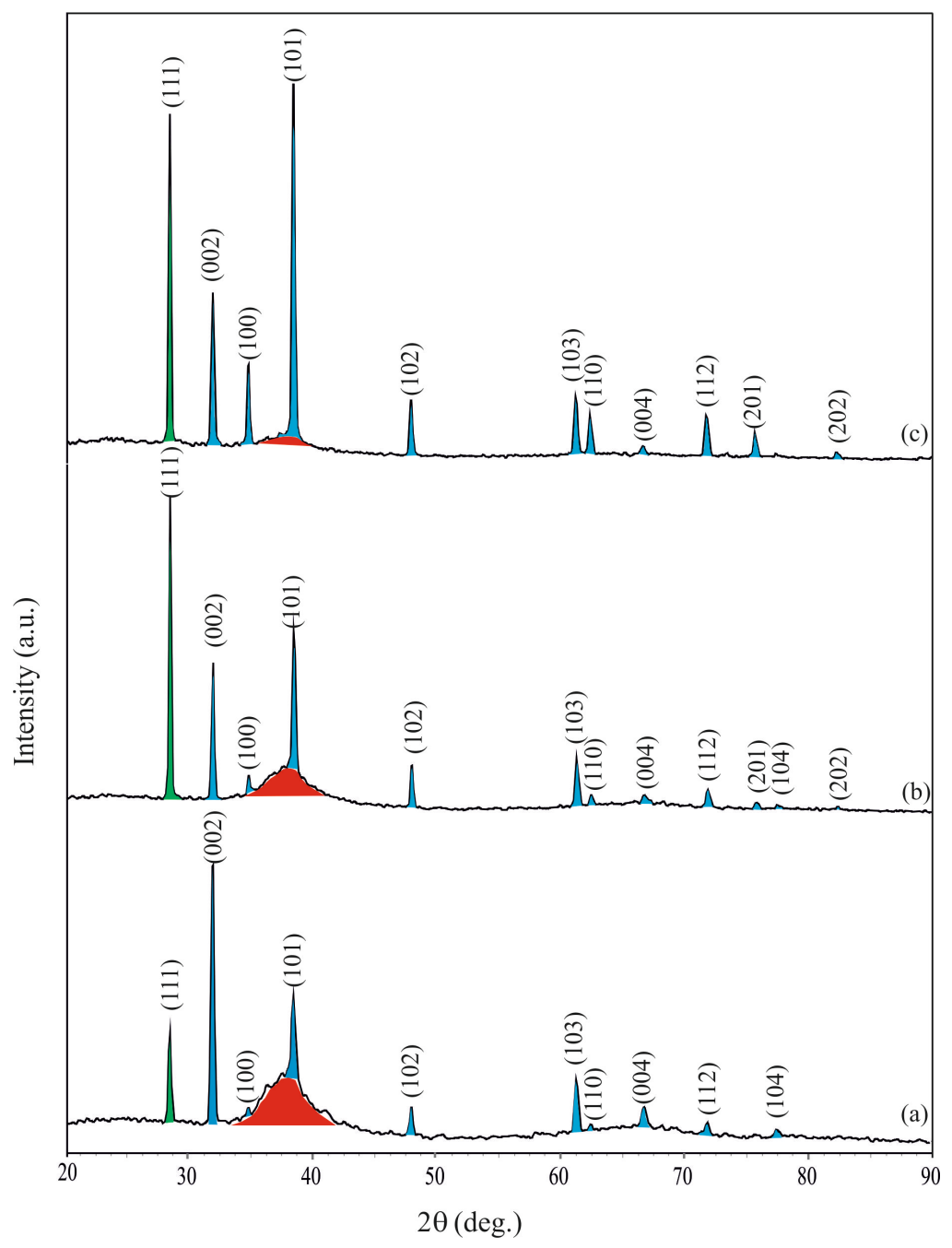

Figure 4. X-ray diffraction patterns of the Ta-Cd coatings with at.\% $\mathrm{Cd}$ : $1-74.4 ; 2-75.4 ; 3-87.6 ; \square-\mathrm{Cd}$; $\square$ -amorphous Ta; $\square-\mathrm{Si}$ (substrate) with orientation (111).

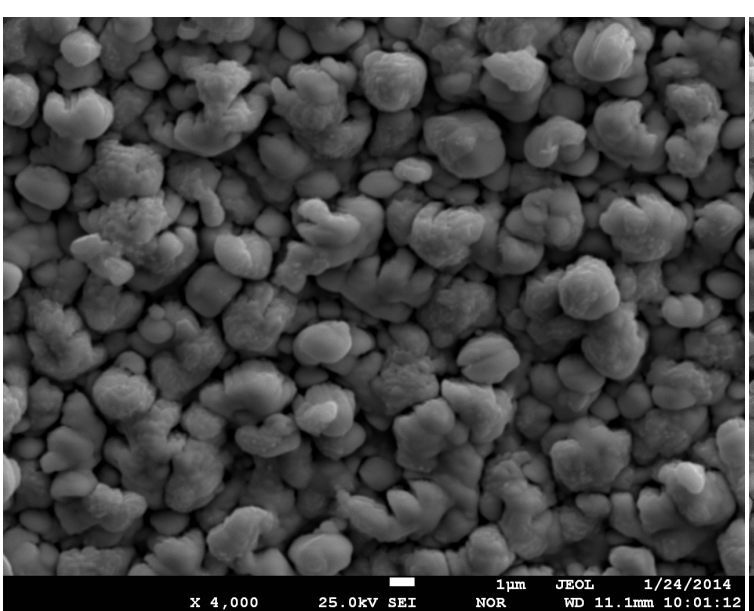

(a)

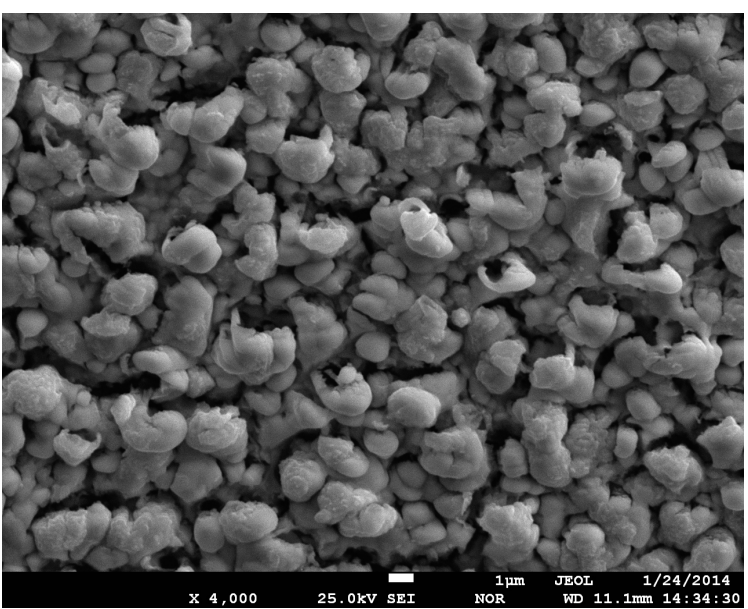

(b)

Figure 5. SEM micrographs of the coating with 74.4 at.\% $\mathrm{Cd}$ in the initial state (a) and after annealing at $700^{\circ} \mathrm{C}$ for 1 hour (b). 
with similar properties.

\section{Acknowledgements}

This study was supported by the Committee for Science of the Ministry of Education and Science of the Republic of Kazakhstan, grant No. 1457/GF4.

\section{References}

[1] Fife, J.A. (1991) Fibrous Tantalum and Capacitors Made Therefrom. Patent US 5306462 A.

[2] Dobrusin, S.Y., Obgolts, O.J., Kachalov, N.A., Frolova, N.M., Chernikov, I.I. and Berezko, V.I. (2011) The Method for Preparation of Fibrous Tantalum Powder and Fibrous Powder of Tantalum. Patent RU 2349423.

[3] Tuleushev, Yu.Zh., Volodin, V.N. and Zhakanbaev, E.A. (2013) Nanosize $\beta$-Tantalum Coatings: Formation, Structure, and Properties. The Physics of Metals and Metallography, 114, 573.

[4] Volodin, V.N., Tuleushev, Yu.Zh. and Zhakanbaev, E.A. (2014) Structure of Niobium-Tungsten Alloy Films Produced by Metal Sputtering. Journal of Surface Investigation. X-Ray, Synchrotron and Neutron Techniques, 8, 1146-1151. http://dx.doi.org/10.1134/s1027451014060160

[5] Volodin, V.N., Tuleushev, Yu.Zh. and Zhakanbaev, E.A. (2013). Structure of Sputter-Deposited Films of $\beta$-TantalumAluminum Alloys. The Physics of Metals and Metallography, 114, 935-939. http://dx.doi.org/10.1134/S0031918X13110136

[6] Volodin, V.N., Tuleushev, Yu.Zh. and Zhakanbaev, E.A. (2015) Structure and Phase Composition of Niobium-Copper Deposited Films. Journal of Surface Investigation. X-Ray, Synchrotron and Neutron Techniques, 9, 178-183. http://dx.doi.org/10.1134/S1027451015010371

[7] Barabash, O.M. and Koval. Yu.N. (1986) The Crystal Structure of Metals and Alloys. Sciences, Kiev, Dumka.

[8] Moseley, P.T. and Seabrook, C.J. (1973) The Crystal Structure of $\beta$-Tantalum. Acta Crystallographica, B29, 1170.

[9] Kwon, K.-W., Ryu, C., Sinclair, R. and Wong, S.S. (1997) Evidence of Heteroepitaxial Growth of Copper on BetaTantalum. Applied Physics Letters, 71, 3069. http://dx.doi.org/10.1063/1.119439

[10] Lee, S.L., Doxbeck, M., Mueller, J., Cipollo, M. and Cote, P. (2004) Texture, Structure and Phase Transformation in Sputter Beta Tantalum Coating. Surface and Coatings Technology, 177-178, 44-51. http://dx.doi.org/10.1016/j.surfcoat.2003.06.008

[11] Arakcheeva, A., Chapius, G. and Grinevich, V. (2002) The Self-Hosting Structure of $\beta$-Ta. Acta Crystallographica, B58, 1-7. http://dx.doi.org/10.1107/S0108768101017918 